\title{
Development strategy of micro house
}

\author{
Wei Zhang, a ,Jun Yang ${ }^{2, b}$ \\ ${ }^{1,2}$ School of Resource and Civil Engineering, Wuhan Institute of Technology, Wuhan, Hubei, China, \\ 430073, \\ ajannet2005@163.com, ${ }^{\text {b28940840@qq.com }}$
}

Keywords:micro house, outdoor space, prefabricated micro house system, products.

Abstract:This paper analyzes residential requirements of low-income class to micro houses. It discusses many practices in China such as capsule houses, youth rental apartment and Vanke micro house. It suggests that micro house design should strengthen outdoor spaces, and develop with prefabricated, productive and intellective methods.

\section{Introduction}

Big cities all over the world are facing the same urgent residential problems for a long term. It is estimated that there will be 3 billion people living in the back slums in cities in 2050. They have low income and live at the edges of society. They live in such constructions as the cage houses, which can be seen in Figure 1, re-divided industrial buildings, illegal roof houses, ships and suburb parks.

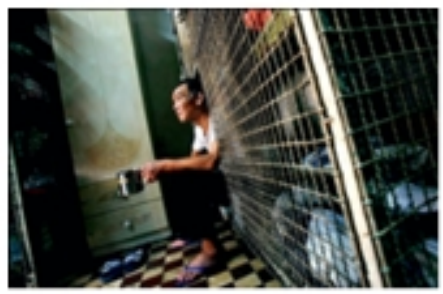

Fig 1. Cage house in Hongkong.

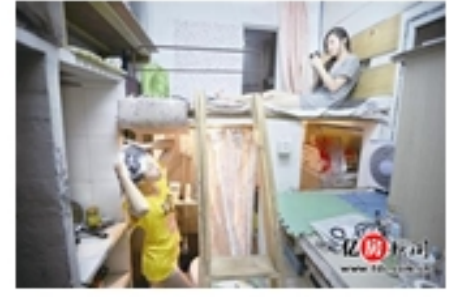

Fig 2. capsule rooms in China.

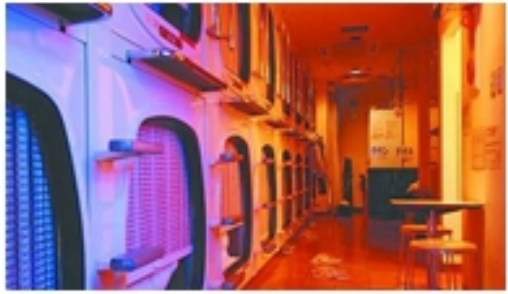

Fig 3. Capsule house in Japan.

Many such residential run short of basic living conditions such as structure to keep out wind and rain, clean drinking water, proper sanitation, heat preservation and insulation.

There are also the same problems appearing in Chinese big cities. House isin shortage, and the price is high.Many people are unable to bear high prices, they can just rent.Residential are converted into multiple small single crowded room "capsule", these capsules are the settlements for them in big cities, as Figure 2 shows.

In the city, the broad masses of low-income groups, such as migrant workers, new university graduates, low income "city ants", they all need a house with complete function, it should be clean andindependent.They need specially designed small space, with well flexibility. They must be cheap, micro and easyto change, and they can meet all the demands of living.

\section{All kinds of microhouse exploration}

Actually, for a long time, whether personal spontaneous or designers consciously exploration on micro house has not stopped.

\section{Capsule house}

The first capsule hotel began to businessin February 1979 in Osaka, Japan. It provides temporary accommodation for the white-collar who works overtime at night. The areais usually within $2 \mathrm{~m}^{2}$ and itis only $1.25 \mathrm{~m}$ high, people can only climb in and out.A bed, a table and a TV arealmost the whole furnitureof the capsule hotel.But because of the cheap price, capsule house in Japan has 
become home for many low-income people to livefor a long time in large cities, as it can be seen in Figure 3.
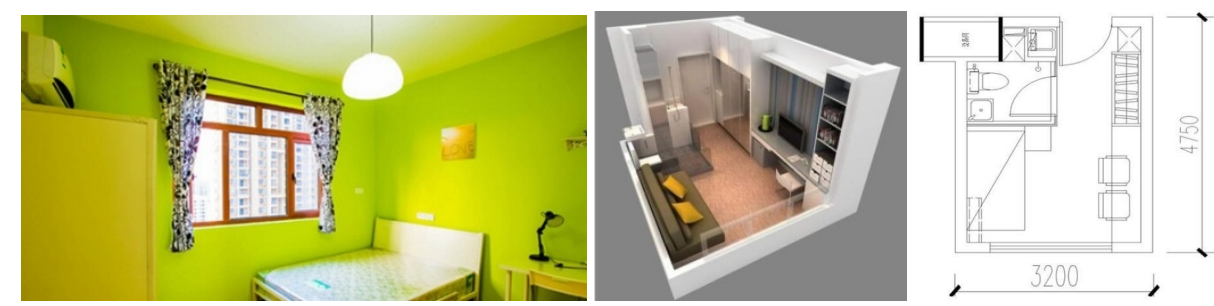

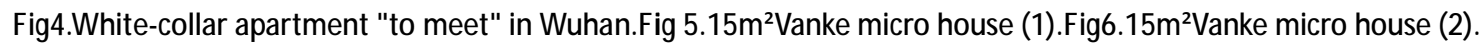

\section{Wuhan white-collar apartment "to meet"}

In China, from 2003 to 2013, these are the ten golden years for real estate, there left over 60 million sets ofsleepy houses in stock for the city. At the same time, the city ants living demand are not satisfied each year. For example, the new university graduates are over 300000 a year in Wuhan.Theseyoung white-collar need a warm home with a little money in big cities.

"To meet" youth apartment effectively combined the needs of both. It renthouse in stock, then decorate it and rent it to young people.Each apartment is about $15 \mathrm{~m}^{2}$ with white furniture, green wallpaper, delicate vase, lovely doll, the photo wall... It has many factors young people love. Bathroom, kitchen, activity room areall complete, and the leisure and entertainment are very convenient, as Figure 4 shows. The house intermediary, decoration companies, Internet Electronic Commerce, property management and health service are all available."To meet" youth apartment are delicate, convenient. These micro rental house are well received by young people.It attracts 10 million Yuan of risk investigation funds from the CEO Lei Jun of XiaomiScientific and Technical Corporation, it has become the largest "middlemen" landlord in Wuhan rental market.

\section{Vanke micro house}

In December 2012, Vanke launched $15 \mathrm{~m}^{2}$ micro houseswith separate bathroom. The total price of each micro house is 90000 yuan. It aimed at young peoplefrom 18 to 25 who have just graduated from university with real estate demands. The Figs. 5-6 show the design of the house.

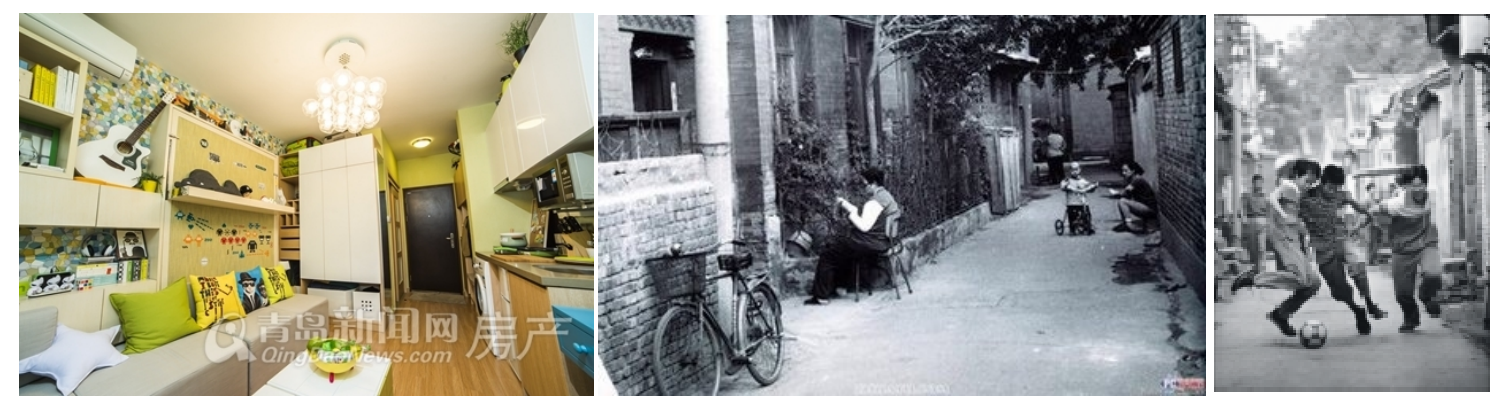

Fig 7.25 $\mathrm{m}^{2}$ VankeMi house.Fig 8.Activities in outdoor space (1).Fig 9.Activities in outdoor space (2).

In October 2014, VankeMi apartment in Qingdaoput forward $25 \mathrm{~m}^{2}$ micro houses with refined decoration. It can satisfy the various needs of family life. The total price is 220000yuan.It locatesat the urban core, with completefunction. It can also be effectivelyrented. It was popular with home buyers. The Figure 7 shows the house design.

As Chinese largest real estate developers, Vanke is exploiting micro houses for low-income people. It tries to develop low-end products. 


\section{Several factors for micro house design}

Architectural design always focuses on the population above middle class. All people have living demands, but only effective demand which has the purchasing power will be satisfied by the market.Only these demands can form the business contract and turn into architects'design task. There are not many micro cheap houses appeared, it can be attributed to the enormous economic benefits combined with the real estate industry.

However, a complete house systemshould meet the livingdemands of different people.It is necessary for us to provide comfortable cheap micro house for low-income people. We should create a dignified life for them. Micro house design should comply with the following trends.

\section{We should attach importance to the design of outdoor space.}

Until the 1980s, many families of three people are living in small house less than $10 \mathrm{~m}^{2}$.No matter rest, eating, sleeping, studying are justin one room, but the outside space is also a part of home.Adults and children spent much time in outside spaces such as the yard and Hutong. Rich experience in the outdoor space and good memories of open neighborhood are the precious memories of Chinese, as Figs. 8 and 9 show. Development of micro house system should also focus on design of outdoor public space. A sense of community and a sense of belonging for those living in the micro houses will be built.

\section{We should develop prefabricated micro house system.}

China has densepopulation, and tense land resources, micro house can be promote and implementonly if it is flexible, variable, efficient and prefabricated.

Architectural design and research institute4A2 architecture studio ofTsinghua University hasa micro house research project - micro house. It is a research project about a prefabricated and integrated house. The interior space of a unitis only $2.4 \mathrm{~m}^{2}$. The section prototype is "Cross".It can accommodate people's basic behavior of "sitting", "sleeping", "standing". Such micro houses can continuouslyconnect along the longitudinal axis and along the vertical axis.Therefore, it can be combined into families or multi-storey building community or cluster community. The Figs. 10-15 show the micro house design.
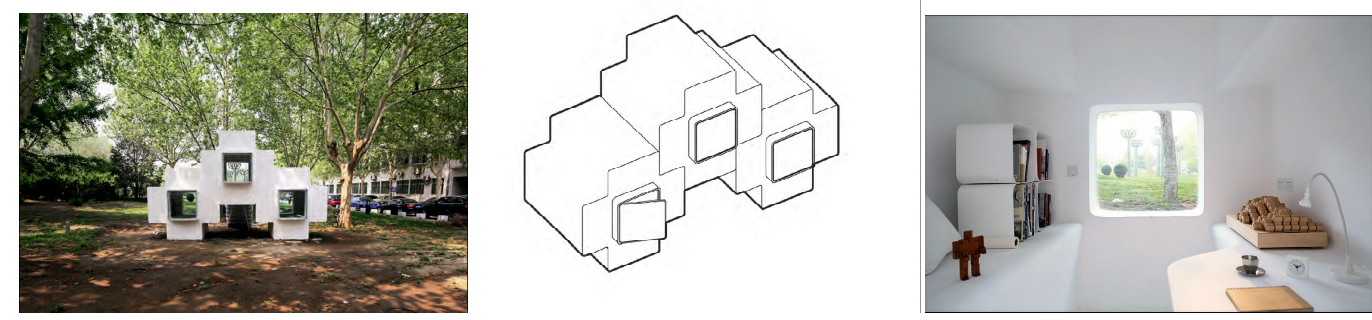

Fig10. Micro house (1).Fig 11.Micro house (2).Fig 12. Interior space of micro house (1).
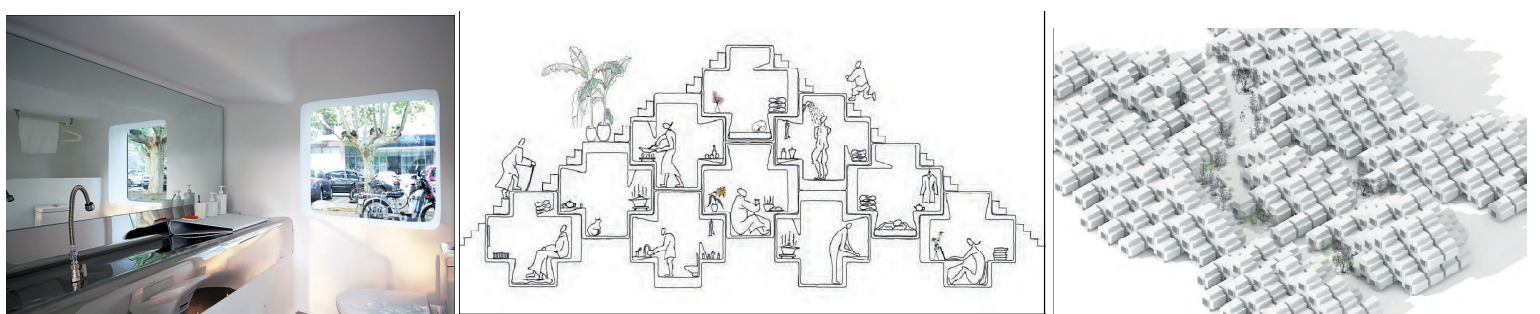

Fig.13 Interior space ofmicroFig14. Multi-storey building communityFig 15.Multi-storey building community andhouse (2).and cluster community (1).andcluster community (2).

The Nakagin Capsule Tower designed byKishoKurokawain 1972 can be seen as the founder of prefabricatedmicro house, it can be seen in Figs. 16-17. The basic unit is $2.3 \mathrm{~m} \mathrm{X} 3.8 \mathrm{~m} \mathrm{X} 3.8 \mathrm{~m}$, the interior space is very simple and delicate, but the function is complete and the integrated design is at 
a high level. It can effectively meet the basic need of a family through the connection and combination of several units.
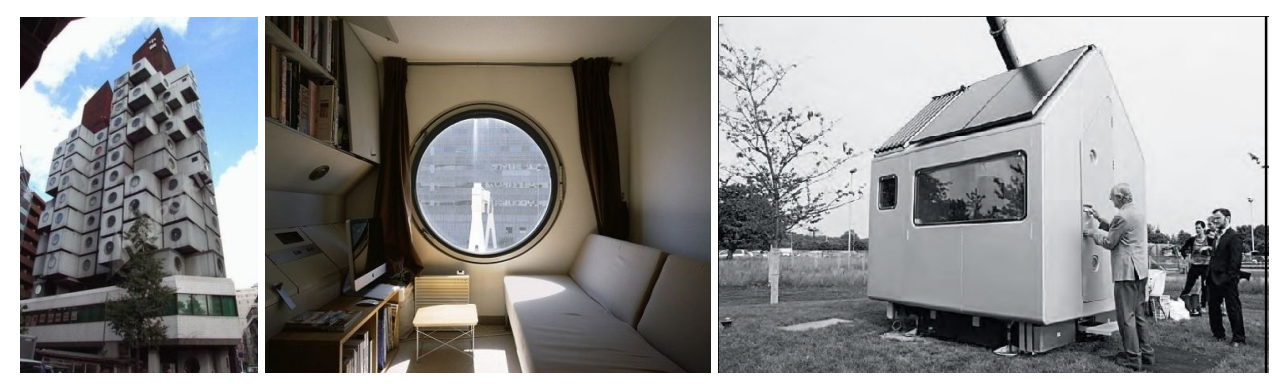

Fig 16.TheNakaginFig 17.A unit of the NakaginFig 18.Diogene house

Capsule Tower.Capsule Tower.designed by Renzo Piano (1).

Micro house should have flexible sizefor different numbers of people to use.It should be modular, can form different configurations, and can reflect the change of life. For example, people move in or move out, the arrival of the children, etc. It can also be combined into community system, to adapt to the high density of city life.

\section{We should think the micro house as products.}

Much big consumption throughout our lives such as education, medical carehas basic state protection. Other consumptions such as cars, household appliances are relatively cheap now.Only the house is very expensive, it is always the lifetimepursuit for many people. The construction cost is high, because it depends on land, and it has huge mass and weight, and it is relatively permanent. If we think about the house as products and try to turn the house into a portable, lightweight, modular, prefabricated, and even portable product, it will be cheap.

If we turn the house into a product, a consumer but not an expensive real estate, it will become cheap. The house should be more industrial and integral.It can be fully completed in the factory assembly line work. It turns the building into a "massive product". Micro houseespecially need such product way so that more people can afford, even afford repeatedly. Micro house can move easily so as to get rid of the land restriction. It will be more personalized.Thus the house consumption purpose will turn into temporary residence, even in order to experience.

As the "IPhone" mobile phone, the micro house should be highly integrated with technology. The building process is completed totally in a factory assembly line. The production process of a mini house is like a car, or a refrigerator. It is equal to buy a house as to buy a household appliance. It can be used when it is carried back home.

At the same time, the decrease of house consumption can reduce the pursuit of higher income. It provides time for people's activities in addition to work for money. It may play a more active rolefor the social development.

Like micro house product "Diogene" products designed by Renzo Piano,as it is shown in Figs. 18-19, the surface is covered by aluminum plate. It has solar panels, rainwater collection and biological purification toilet. This micro house product can be used when you carry it back.

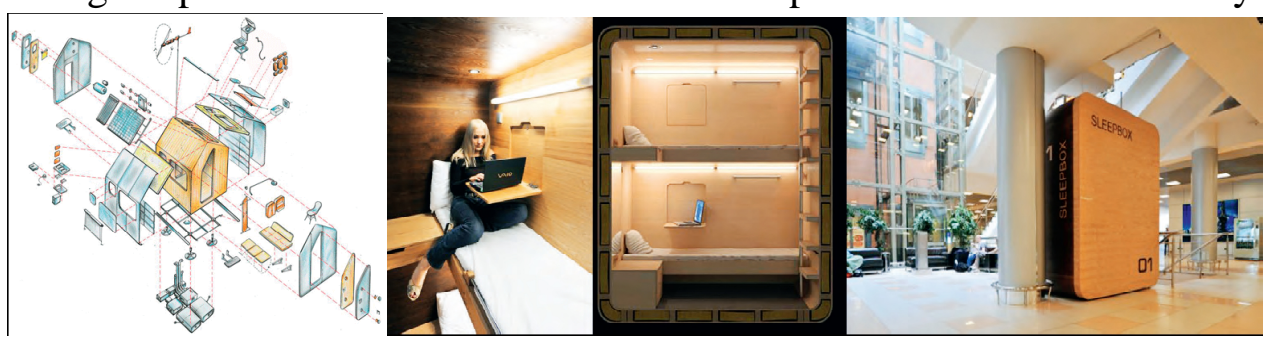

Fig19.Diogene house designed by Renzo Piano (2).Fig 20.Sleep Box in the airport. 


\section{We should use intelligent management platform in micro house.}

Bill Gates once said: in the near future, it is unfashionable without the smart home system just like the house can't surf the Internet today.Despite "robot era" intelligent system is still far from us, it will probably appear in the next 20 years or 15 yearsat the level of development of science and technology today.

Micro house aims at a new kind of house product.It should be combined with intelligent management platform.If the minihouse isa kind of hardware, Intelligence partsand integration system should become the necessary "software".

Just like the Sleep Box designed by Russian for the airport, as it is shown in Figure 20.The box area is only $2.8 \mathrm{~m}^{2}$ and it is $2.8 \mathrm{~m}$ high.The room ventilationsystem, liquid crystal display television, wireless Internet access,power socket and luggage space are all highly component integrated.

\section{Conlusions}

No matter in Hong Kong, Japan, or mainland China, each big city has certain people demands for cheap, comfortable, fully functioning micro house. Part of the houses turn intomicro, prefabricated, intellectualized and productive is the inevitable development trend.Architectural design should adapt and guide the evolution of the micro house.

\section{References}

[1] L.B. Liu: submitted to Journal of Community Design, 01( 2014): 38-41.

[2] Y .Liu: submitted to Journal of Community Design, 01( 2014): 48-50.

[3] Z.S.Liu: submitted to Journal ofBuilding Structures,S2( 2014): 29-33.

[4] Y.Jing: submitted to Journal ofWall Materials Innovation \& Energy Saving in Buildings, 04( 2014): 12-15.

[5] C.D.Wu: submitted to Journal ofShenyang Architectural and Civil Engineering Institute,01( 2015): 63-66. 